\title{
JOVENS E VIOLÊNCIA NA CIDADE DE LONDRINA - PR
}

\author{
Young and Violence in the City of Londrina
}

Pof ${ }^{a}$. Dra . Márcia Siqueira de Carvalho

Bolsista Produtividade Fundação Araucária - PR

Universidade Estadual de Londrina, Departamento de Geociências.

Campus Universitário, CEP: 86051-990 - Londrina (PR) - Brasil

Tél:/Fax: (+ 55 43) 33714246 / 33714216 - marcar@uel.br

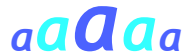

\begin{abstract}
Resumo
O aumento crescente do número de mortes entre jovens do sexo masculino é uma variável que geralmente traduz a forma mais extrema da violência. A inserção da cidade na rede de atividades ilícitas, em especial o tráfico de drogas, é uma referência importante no estudo da violência urbana, em especial da criminalidade urbana. As relações de poder e políticas devem ser levadas em conta para a compreensão desses fenômenos. $\mathrm{O}$ artigo teve como objetivo a elaboração de um sucinto painel da morte de jovens na cidade de Londrina. Para isso procedeu-se o levantamento e análise da literatura, incluídos artigos, dissertações, relatórios de pesquisa nas áreas da Sociologia, Saúde Pública, Antropologia, e da Geografia, notícias publicadas em jornais e dados do SIM e do SIATE. Assim como uma breve lista de dados que possibilitam a caracterização do tema. Londrina, uma cidade média em termos de população e de funções urbanas mais complexas mostra-se ideal como campo de trabalho e de reflexões a respeito do assunto.
\end{abstract}

Palavras-chave: Londrina, violência urbana, homicídios.

\begin{abstract}
The increasing deaths between young males are the variable that generally translates the extreme form of the violence. The insertion of the city in the net of illicit activities, in special the traffic of drugs, is an important reference in the study of the urban violence, in special of urban crime. The relations of power and politics must be taken in account for the understanding of these phenomena. The article aims to draw up a short panel of Londrina's young adulthood deaths. To accomplish that with a survey and analysis of literature, including papers, research reports in the areas of Sociology, Public Health, Anthropology, and Geography, news published in newspapers and SIM and SIATE data. Just as a brief list of data that enable the characterization of the issue. Londrina, a medium city in terms of population and more complex urban functions reveals as ideal field of work and reflections regarding the subject.
\end{abstract}

Key words: Londrina, urban violence, homicides.

\section{Resumen}

El aumento de las muertes entre los varones jóvenes es la variable que traduce generalmente la forma extrema de la violencia. La inserción de la ciudad en la red de actividades ilícitas, en especial el tráfico de drogas, es una referencia importante en el estudio de la violencia urbana, en especial del crimen urbano. Sin embargo, los parámetros de la evaluación de la violencia podrían incluir el número de los accidentes de tráfico y la identificación de las redes ilegales, que pueden estar más allá de los límites urbanos. El artículo tiene como objetivo la elaboración de un panel corto de la muerte de los jóvenes en la ciudad de Londrina. Para esta encuesta se llevó a cabo y el análisis de la literatura, incluidos los documentos, informes de investigación en las áreas de Sociología, Salud Pública, Antropología y Geografía, las noticias publicadas en los periódicos y datos de SIM e SIATE. Así como una breve lista de datos que permiten la caracterización de la cuestión. Londrina, una ciudad mediana en términos de la población y de las funciones urbanas mas complejas revela como campo ideal del trabajo y de las reflexiones con respecto al tema.

Palabras clave: Londrina, violencia urbana, homicidios.

$$
\text { åa a }
$$




\section{INTRODUÇÃO}

A violência tem um significado amplo, envolvendo um ou mais atores de maneira direta ou indireta, cujos danos são variáveis desde a integridade física, moral, de posses ou participações simbólicas e culturais (MICHAUD, 1989 apud WAISELFISZ, 2007, p. 13). Tornou-se comum a expressão da violência urbana através do número de óbitos por faixas etárias, sua relação por mil habitantes ou de número de anos potenciais de vidas perdidas. Nesse contexto, a relação entre violência, criminalidade e condições econômicas tem sido dominante nas análises acerca do tema, cuja configuração espacial tem se baseado na "cidade partida", na reprodução da desigualdade ao acesso ao trabalho formal, moradia, saúde, entre outros (MARICATO, 1996). A análise da violência urbana e suas causas no contexto dos limites da cidade abordam as diferenças reveladas por índices (IDH), e aponta as desigualdades como sua impulsionadora. Alguns estudos tratam da apropriação de novos espaços por condomínios fechados em contraposição às ocupações por favelados de espaços, na maioria públicos e por vezes de preservação ambiental. Neles foi estabelecido a priori que a desigualdade entre os que têm muito e os que têm muito pouco (ou nada) é a principal explicação da violência urbana (MISSE, 1995 e 2007). No âmbito da Geografia Souza (1998) alerta para o equívoco do reducionismo economicista de esquerda e dos vieses institucionalista e culturalista dessas abordagens em estudos sobre a criminalidade e violência a partir de seus estudos na cidade do Rio de Janeiro. Sua crítica defende a necessidade de uma conexão não-simplista entre injustiça social e criminalidade.

O tema também é pesquisado na abordagem da Saúde Pública. As análises de morbidade e mortalidade classificadas em "causas externas" podem identificá-las como um problema epidêmico. Nesse contexto, a violência urbana também envolve as condições de existência de determinada população. Os dados utilizados por profissionais da Saúde Pública (MINAYO, 2007) permitem uma espacialização da informação - os óbitos por causas externas - numa escala intraurbana das Unidades Básicas de Saúde. Eles são um ponto de partida para a identificação desse tipo de morte, sua distribuição por faixas etárias e demandam informações em outras fontes. Sob a classificação de morte por causas externas estão aquelas que ocorreram por agressões, acidentes de transporte, suicídios e outras. Nesses trabalhos são utilizados os dados do Sistema de Informação de Mortalidade (SIM) do Ministério da Saúde em escalas espaciais nacional, macrorregional, estadual, municipal, e de regiões metropolitanas e aglomerados urbanos.

A escala dos setores do Censo Demográfico do IBGE (microdados) possibilita reunir informações sobre renda familiar, número de jovens por faixa de idade, escolaridade e condições de habitação, importantes na caracterização do espaço de áreas dentro de uma cidade. Infelizmente sua base cartográfica é diferente da área de atuação das Unidades Básicas de Saúde (UBS), a menor escala de informação cujos dados não estão na base pública do SIM. Os microdados do Censo não trazem informações sobre o número de mortes violentas, mas possibilitam identificar perfis distintos de seus habitantes.

Outra fonte de informação são os Boletins de Ocorrência registrados em delegacias e os atestados de óbitos após autópsias em Instituto Médico Legal (IML). Embora se reconheça o fato das subnotificações no registro de Boletins de ocorrência, obrigatórios somente quando houve morte. Porém o acesso ocorre após a aprovação do projeto antes de seu início por um comitê de Bioética, da mesma maneira para ter acesso aos dados de local de residência e de causa da morte na escala intra-urbana. Em Londrina reporta-se à Autarquia de Saúde do Município.

A base de dados do Sistema de registro e estatística de ocorrências (SIATE) da cidade de Londrina possibilita a localização por logradouro e bairro, embora não tenha uma base cartográfica própria o que remete à adequação da localização aquela dos bairros. No presente artigo foram analisados dados do SIM na escala municipal e do SIATE para bairros (intra-urbano). 
A análise desses dados diversos permite uma aproximação à questão da violência urbana e a morte violenta de jovens tem um papel destacado, embora não seja o único. Porém, a discussão sobre o contexto em que elas acontecem é mais complexo, com variáveis distintas.

\section{FATORES DA VIOLÊNCIA URBANA}

A primeira contribuição vem da discussão realizada por sociólogos e antropólogos brasileiros se as mortes violentas de jovens podem ser consideradas como o resultado da pobreza e de fluxos migratórios. Em pesquisa realizada envolvendo dados entre 1981 a 1989 para os estados brasileiros a relação direta entre pobreza e violência não se confirmou (ZALUAR; NORONHA; ALBUQUERQUE, 2007). No Rio de Janeiro, estado mais violento na época,- os crimes contra a pessoa tiveram aumento (duplicaram) antes de 1988, ano em que houve um aumento na proporção de pobres. Roraima e Rondônia, estados tão violentos quanto o Rio de Janeiro, se caracterizaram pela existência de frentes de expansão, garimpo e tráfico de drogas. As duas primeiras atividades ocorrem quando a estrutura fundiária ainda não se estabilizou e a grilagem é a forma mais freqüente de apropriação privada da terra, resultando em conflitos e mortes. A violência na cidade do Rio de Janeiro foi analisada sob outros fatores. Um conjunto de situações organizado em redes que tinham articulações entre si revelou que o processo de invasões de terrenos públicos que beneficiaram grileiros e cabos eleitorais tornou tensas as relações sociais nesses novos bairros. A ocupação das calçadas por camelôs "misturou uma saída para o desemprego com o crime organizado, este ainda mais patente nos ferros-velhos e ourivesarias, que viraram centros de receptação e de organização do crime" (ZALUAR; NORONHA; ALBUQUERQUE, 2007, p. 215).

Trabalhos mais recentes destacaram a "interiorização" da violência, pela reprodução do ambiente violento das grandes metrópoles em cidades médias a partir do incremento das taxas de mortalidade por acidentes de trânsito, homicídios e uso de armas de fogo, observada desde 2004 (WAISELFISZ, 2007). As principais características da violência extrema não se alteraram. As taxas de homicídio nos revelam que são geralmente jovens do sexo masculino, com idade entre 15 e 24 anos, concentradas entre 20 e 24 anos, mas com ritmo crescente na faixa de minoridade - 14 aos 17 anos, aos finais de semana, majoritariamente negros, exceto no Acre, Tocantins e Paraná (WAISELFISZ, 2007, p.23-24). O porquê do aumento das mortes dos jovens do sexo masculino nos leva a buscar apoio na estrutura sociológica que domina esse território e as suas temporalidades.

\section{A ESTRUTURA SOCIOLÓGICA DOS NÍVEIS DE VIOLÊNCIA}

Uma análise interessante ao tema relacionando as estruturas sociológicas e os níveis de violência urbanos sobre por que ela aumentou nas cidades latinoamericanas nos últimos vinte anos veio de Briceño-León (2005). Ele considerou três estruturas sociológicas que envolvem os habitantes de uma cidade.

A primeira estrutura abrange o processo social mais geral (macro) e sua temporalidade é mais longa. Nela se encontram os fatores que atingem a sociedade como um todo, cujos resultados são difusos e generalizados. Dificilmente se poderá fazer uma associação imediata com o comportamento violento. Ela não é determinante no sentido de que a violência obrigatoriamente deverá acontecer, mas deve ser considerada como "primeira causa" e conjunto de circunstâncias que são mais difíceis de serem modificadas. Nessa estrutura estão presentes as discussões sobre a desigualdade de oportunidades entre as pessoas que moram nas cidades, a distribuição desigual de renda que constrói no espaço urbano os espaços da exclusão e que concentram ao mesmo tempo maior riqueza e maior pobreza.

Também é nessa esfera que ocorrem as relações entre emprego/desemprego e escolaridade/ evasão escolar, embora não obrigatoriamente haja mais emprego quando existem maiores taxas de escolarização (matrículas). O desemprego atinge os jovens, em especial os do sexo masculino e 
os jovens fora da escola e sem emprego ficam mais expostos aos ambientes violentos. Eles têm os mesmos desejos de consumo dos demais adolescentes, embora não tenham condições de realizá-los.

O controle social exercido pela família ou pela religião vem sendo substituído pelas aspirações da sociedade de consumo, num contexto em que o papel socializador da mãe e a autoridade do pai vêm perdendo a importância nas famílias mononucleares ou que perderam a figura paterna. $\mathrm{O}$ enfraquecimento da religião deve ser visto como o afastamento do cumprimento de regras próprias da não violência (não roubarás, não matarás), apesar da religiosidade não impedir seus seguidores de sofrerem com a violência. Pesquisas que têm como objeto esse nível estrutural mais amplo poderão fazer associações bastante gerais, não dando conta das especificidades, em explicar porque alguns e não todos.

O segundo nível abarca aspectos meso-sociais os quais envolvem a cultura, a situação (características relativas à qualidade do espaço geográfico), a presença do tráfico de drogas e a impunidade que influem sobre o comportamento dos indivíduos e comunidades (BRICEÑO-LEÓN, 2005, p. 1639). Eles fomentam a violência e podem ser modificados mais facilmente do que a estrutura anterior. É nesse nível que cabe a discussão dos territórios ocupados (ou dominados) por relações sociais de violência, como os do mercado do tráfico de drogas ou da atuação de milícias ou de para-militares. Ainda, a queda nas rendas das famílias dificulta a reforma das residências ou sua manutenção, além da limitação do espaço físico dos terrenos à medida que a família se multiplica com os casamentos e a vinda dos netos. Esse fato provoca o crescimento vertical das habitações e a procura de novos sítios para a reprodução de moradias irregulares e sem infraestrutura.

Lugares densamente povoados e com infraestrutura precária e violentos perdem valor no mercado imobiliário, reforçando o estabelecimento de novos habitantes igualmente pobres. Favelas, com becos e vielas, assim como o fator topográfico (morros), parecem ser mais facilmente controláveis por grupos criminosos e a defesa do terreno mais fácil à ação da polícia. Barrios da Caracas venezuelana (BRICEÑO-LEÓN, 2005, p. 1640) e favelas cariocas são exemplos dessa especificidade do espaço geográfico.

Os números desiguais quanto ao gênero quando se trata das mortes de jovens leva os sociólogos a incluir em seus estudos a cultura da masculinidade e da virilidade. Atitudes que evitam o conflito são tidas como atitudes femininas, ainda mais numa sociedade machista na qual os adolescentes passam por uma fase de identificação e definição de papéis. A exposição aos riscos acaba se tornando uma espécie de ritual de masculinidade, exacerbada nos ambientes violentos em ritual de passagem da infância à fase adulta. Embora ficção, o menino que afirmava ser adulto por ter matado alguém numa cena do filme Cidade de Deus vale como exemplo desse rito no tráfico de drogas. A violência também está associada em conseguir o respeito dos demais num ambiente em que jovens e pobres desempregados têm poucas chances de usufruir da sociedade de consumo. O tráfico de drogas é essencialmente violento porque geralmente a morte é o resultado do não pagamento de dívidas. Caso o consumidor ou o pequeno traficante não pague suas dívidas, há a execução.

$\mathrm{O}$ crescimento de consumidores reforça a disputa pelo território, levando às brigas entre grupos (gangues). A estrutura do tráfico ao apoiar financeiramente e juridicamente seus empregados ocupa o vácuo do Estado e da família, cria dialeticamente uma rede social de proteção, com características sui generis. Ao mesmo tempo oferece regras de comportamento nas áreas onde domina (favelas, morros) aplicando uma justiça violenta aos transgressores (ladrões, estupradores, etc.) e controladora do tempo dos moradores (toque de recolher) e do lugar (proibição de freqüentar locais de outros traficantes). Bailes funk no Rio de Janeiro, por exemplo, são organizados com o objetivo de marcar presença territorial e oferecer festas e local de promoção de determinado traficante. Pode-se observar que o mercado do tráfico de drogas é essencialmente territorial ao delimitar espaços sob determinadas relações de poder.

.A corrupção é outro fator que fomenta a violência, em especial quando parcelas do Estado que deveriam impedir o crime fazem parte dele, extorquindo, fornecendo armas ou facilitando fugas. 
Não é correto classificar isso de coronelismo urbano, mas há semelhanças pelo mandonismo local, autoritarismo, impunidade e controle de votos nas eleições.

O terceiro nível diz respeito aos fatores micro-sociais (facilitadores da violência) característicos da natureza mais individual e que devem ser considerados como associações do que causalidades. Neles, a facilidade de acesso às armas de fogo, o consumo de álcool e a incapacidade de resolver problemas pelo diálogo. Podemos destacar duas campanhas desenvolvidas no Brasil na escala nacional, uma em relação ao recolhimento de armas de fogo e outra na restrição de bebidas aos motoristas. E as leis aprovadas por câmaras municipais de algumas cidades sobre o fechamento dos bares a partir de determinado horário durante a noite.

Todas as três instâncias sociais auxiliam no entendimento da violência nas cidades, assim como os fatores identificados na cidade do Rio de Janeiro por sociólogos, antropólogos e geógrafos.

\section{RELAÇÕES DE PODER NO ESPAÇO URBANO LONDRINENSE}

As relações de poder existentes numa cidade devem ser consideradas, mesmo que algumas não apresentem riscos tão perigosos quanto à morte. Produtos ilegais vendidos livremente a partir de uma rede de contrabando e significam a diminuição de pagamento de impostos, a informalidade e a diminuição de investimentos em serviços públicos. A concorrência com o comércio ilegal pode trazer a diminuição de postos de trabalho formais e a recorrência ao emprego informal e têm repercussões em longo prazo nas condições de vida no momento da aposentadoria. A informalidade também não respeita a legislação do trabalho infantil e adulto. Em termos econômicos e trabalhistas os prejuízos se acumulam ao longo do tempo. Na esfera política, a negociação do voto para obter os serviços de infraestrutura nos bairros mais afastados caracteriza o vínculo assistencialista subordinado à formação de currais eleitorais. Ela não oferece os direitos do cidadão sem uma contrapartida nos momentos de eleição. Afetados diariamente nas condições de moradia e de vida em sua cidade, os moradores esperam por vários anos para ter rede de esgoto, ruas asfaltadas, escola, emprego formal e segurança pública. Formado o círculo vicioso, resulta na falta de empregos, em especial aos jovens, e de investimentos em moradia para a população mais carente e moradora nas ocupações irregulares.

A Prefeitura de Londrina foi ocupada por Antonio Belinati em três ocasiões (1976, 1988 e 1996) quando ele incentivou a ocupação de áreas públicas por favelas e construiu conjuntos de moradias populares afastados do centro sem a infra-estrutura completa. A cada eleição a promessa feita era de estender as melhorias como asfalto nas ruas, o que possibilitava a entrada de ônibus, construção de escolas, creches, praças, etc. Ao mesmo tempo, insinuava que o acesso à moradia seria mais fácil na cidade, apoiando ocupações irregulares através de cabos eleitorais, atividade incrementada às vésperas das eleições municipais. A conjuntura favorável à construção de moradias populares para a população favelada na metade da década de 1970 contribuiu para as reeleições e criação de eleitores cativos. A fidelidade do voto nesse político se mantém após a visível melhoria de condições de renda dos primeiros beneficiados nos vários conjuntos habitacionais na região Norte da cidade, distantes até oito quilômetros da área central. Nos períodos eleitorais, os bairros Parigot, Vivi Xavier e Cinco Conjuntos no Norte da cidade e porções norte do Pacaembu, Autódromo e Ouro Verde são considerados como definidores dos resultados. Emblematicamente, o local de comemoração das vitórias não é o centro da cidade, mas a avenida principal da área, a Saul Elkind. Os bairros podem ser identificados na Figura 2.

Em 1989 Belinati destinou uma área para assentamento batizado de União da Vitória a um grupo de sem terra da área rural do município em decorrência de uma reintegração de posse. Nesses anos ainda era uma ocupação irregular com 477 unidades (COAHB, S/D). O Jardim União da Vitória II, vizinho ao anterior, foi iniciado em setembro de 1992 tinha 1.573 unidades . O início da instalação do primeiro foi uma sucessão de ocupações e reintegrações de posse do terreno pertencente 
à COHAB-Londrina durante a prefeitura anterior de Wilson Moreira (1983-1988). Tonela (1997, p. 144-168) descreve detalhadamente esse longo processo na ótica dos movimentos sociais e dos sem terra urbanos de origem rural, e conclui a respeito do União da Vitória:

Posteriormente, sua ocupação foi estimulada na gestão do prefeito Antonio Belinatti do PDT (19881992) que, no entanto, não garantiu à população os equipamentos sociais mínimos, como saneamento básico, escola, posto de saúde e policiamento. (TONELLA, 1997, p. 143)

Político envolvido em muitas polêmicas, em maio de 2000 a Justiça já havia determinado o seu afastamento por utilizar recursos do município em gastos com publicidade para promoção pessoal. Em junho de 2000 a Câmara Municipal de Londrina cassou o seu mandato. Uma série de recursos permitiu sua eleição para deputado estadual em 2004 e disputa na eleição para prefeito em 2008. Nessa ocasião recebeu uma votação expressiva tanto no primeiro quanto no segundo turno quando ganhou com mais de 100.000 votos (GOUVEIA, 2006; e Quadro 1). Só não assumiu a prefeitura em 2008 pela cassação do registro de sua candidatura pelo Tribunal Superior Eleitoral (TSE). A origem de sua cassação não foi pela política clientelística, mas porque o Tribunal de Contas estadual rejeitou a prestação de contas de um convênio com o Departamento Estadual de Estradas de Rodagem para manutenção de estradas rurais, em 1999. Isso o tornaria inelegível. Com base no julgamento, o Ministério Público Eleitoral conseguiu que o Tribunal Regional Eleitoral cassasse o registro de sua candidatura. Belinati recorreu ao TSE, que havia autorizado a manutenção da sua candidatura até o julgamento do mérito, que ocorreu em outubro de 2008, decidindo pela cassação. Após tantos anos, Belinati tem votos cativos e conseguiu ampliar seus eleitores (Quadro 1).

Quadro 1. Eleições e votos em Antônio Casemiro Belinati

\begin{tabular}{|l|l|r|c|}
\hline \multicolumn{1}{|c|}{ ANO } & \multicolumn{1}{|c|}{ TIPO } & VOTOS VÁLIDOS (NO.) & VOTOS VÁLIDOS \% \\
\hline 1976 & Prefeito & 36.198 & sem informação \\
1988 & Prefeito & 68.951 & sem informação \\
1996 & Prefeito (2‥ Turno) & 105.988 & 52,7 \\
2004 & Prefeito (2‥ Turno) - 2‥ Lugar & 121.102 & 46,7 \\
2008 & Prefeito (1‥ Turno) & 98.432 & 36,4 \\
& Prefeito (2‥ Turno - anulado) & 138.926 & 51,7 \\
\hline
\end{tabular}

Fonte: Paraná. TRE (S/D)

Outros prefeitos têm lidado com as ocupações irregulares recentes, geralmente situadas em áreas de preservação ambiental, com o receio de resultados eleitorais futuros e a falta de verbas. Embora poucas se comparadas a outras cidades, são locais de exclusão e segregação. Não é uma relação simples e pesquisas que identificassem as relações políticas entre eleitores, prefeitos e vereadores no acesso à moradia e modificações no uso do solo urbano, propiciando (ou não) a especulação urbana e a ocupação irregular seriam bem vindas.

\section{MORTES VIOLENTAS DE JOVENS EM LONDRINA}

Numa primeira aproximação ao problema da violência urbana na cidade de Londrina (Figura 1), centro da região metropolitana e sede da microrregião geográfica foi adotado o número de mortes violentas, em especial entre jovens.

Na revisão bibliográfica os resultados encontrados por Zequim (2004) descreveram que Londrina em 2002 acompanhou a tendência brasileira no que diz respeito às causas de mortes: doenças do aparelho circulatório $(32,9 \%)$; neoplasias $(19,1 \%)$ e causas externas $(12,6 \%)$. Entre essas, próximo 
da metade (44\%) ocorreram por agressões, seguidas de acidentes de transporte (28,6\%). Anteriormente, entre 1994 e 2000, os acidentes de transportes eram o principal responsável por mortes de causas externas, seguidas dos homicídios. Provavelmente a readequação viária, contratação e capacitação de agentes de trânsito e melhoria do atendimento por equipes de paramédicos e médicos no local do acidente (SIATE), permitiram que o número de mortes ficasse estável após uma queda.



Figura 1 - Município e área urbana de Londrina 
Os homicídios em 2001 aumentaram de 16,10 para 26,82 para cada grupo de 100.000 habitantes. Entre 1995 e 2000 eles estavam em queda e a partir de então se observou uma curva ascendente: em números absolutos, 73 em 2000, 125 em 2001 e 164 em 2002 (ZEQUIM, 2004). As vítimas eram majoritariamente do sexo masculino, $1 / 3$ das mortes ocorreu entre as $20 \mathrm{~h} 00 \mathrm{~min}$ e $24 \mathrm{~h} 00 \mathrm{~min}$, concentrando-se nos finais de semana. Em todos os anos analisados as vítimas que tinham entre 18 e 24 anos ficaram em torno de $35 \%$ do total. O tipo de arma utilizado em todos os homicídios predominou a arma de fogo (69\%).

Em 2000 a área urbana de Londrina contava com 433.369 habitantes. Em 2005 a população mais excluída residia nas ocupações irregulares $(1,8 \%)$, assentamentos e favelas urbanizadas em áreas regularizadas (5\%), ocupações irregulares em áreas particulares $(0,4 \%)$ e assentamentos e favelas em áreas aptas a serem regularizadas (3,4\%). Ao todo, 10,6\% dos seus habitantes residiam nas áreas mais críticas (LONDRINA, 2005/2006). A espacialização da residência de jovens e adolescentes a partir das informações do Censo Populacional de 2000 na escala de microdados mostra a sua predominância em bairros como o Jardim Olímpico, Cidade Industrial 2, União da Vitória, Cidade Industrial, Vivi Xavier, Lon Rita, Saltinho, Chácara São Miguel e parcelas do Parque das Indústrias, Lindóia, Ideal, Pacaembu, Parigot, Coliseu, Interlagos e Cafezal (ARCHELA; BARROS, 2009, p. 125-6). Esses dados são importantes na localização das mortes violentas de jovens entre 2000 e 2002 comparados os locais de residência e os locais do óbito de algumas ocupações irregulares - favelas e assentamentos. Em 2001, o Assentamento João Turquino, Maracanã e seu entorno (zona Oeste), e Jardim Nossa Senhora da Paz e Vila Marízia, Grilo da Caixa Econômica (ou Favela da Bratac) mais próximos do Centro (Figura 2) apresentou uma taxa de 43,99 homicídios em cada grupo de 100.000 habitantes.

O município registrou um aumento nos assassinatos de 125 para 164 entre 2001 e 2002, aumentando a taxa de homicídios de 29,14 para 37,34 por 100.000 habitantes. Isso se deveu às mortes registradas na região Leste (Favela São Rafael, Assentamentos Santa Fé e Monte Cristo e ocupações da região Oeste no fundo de vale do Córrego Água das Pedras), respectivamente com 54,22 e 53,19 mortes por 100.000 habitantes (ZEQUIM, 2004). Para melhor compreensão do problema, ver as figuras 2 (Bairros) e 3 (territorialização das mortes). Mais à frente pode ser constatado que esse quadro de mortes violentas aumentou no ano de 2003, embora sem o detalhamento das faixas de idade e locais de residência e do óbito.

Segundo o delegado responsável pelo setor de homicídios da $10^{\text {a }}$ SDP na época, as mortes relacionadas ao narcotráfico e crime organizado em Londrina são caracterizadas pela execução sumária Entre 2000 e 2002, o perfil das vítimas apontou para jovens, na maioria desempregados, em que pese a escassa informação a este respeito. Pouco mais da metade foram mortos num raio inferior a 500 metros de sua residência (ZEQUIM, 2004). Em Londrina o aumento dessas mortes estava relacionado ao aumento de drogas ilícitas entre jovens transformados em vendedores (BARÃO, 2002), e a maioria das mortes ocorreu em função de dívidas e brigas de gangues. Zequim (2004, p. 93) dá uma descrição mais detalhada:

Segundo os investigadores entrevistados, em todas as favelas e assentamentos de Londrina há a presença do tráfico de drogas. Porém, alguns (mas) são controlados (as) por traficantes "fortes", ou seja, que possuem maior domínio do território e armamentos. Esses territórios, segundo nossos entrevistados, são: Favela São Jorge e Nossa Senhora Aparecida (zona norte); Favela do João Turquino 1, Maracanã, Nossa Senhora da Paz (Bratac), Pantanal e Leste Oeste (zona oeste); Favela Novo Amparo, Santa Fé, Monte Cristo e Rosa Branca (zona leste); Favela Marizia (zona central); Favela do Franciscato e Assentamento União da Vitória (zona sul). Citaram ainda como bairros urbanizados onde é marcante a presença de pontos de distribuição de drogas ("bocas"): os Jardins Santiago e Leonor e parte dos Conjuntos Habitacionais da zona norte da cidade. Se olharmos os mapas da distribuição de homicídio por local de ocorrência [...], verificamos que são exatamente nesses lugares onde ocorre a maioria dos homicídios na cidade. 


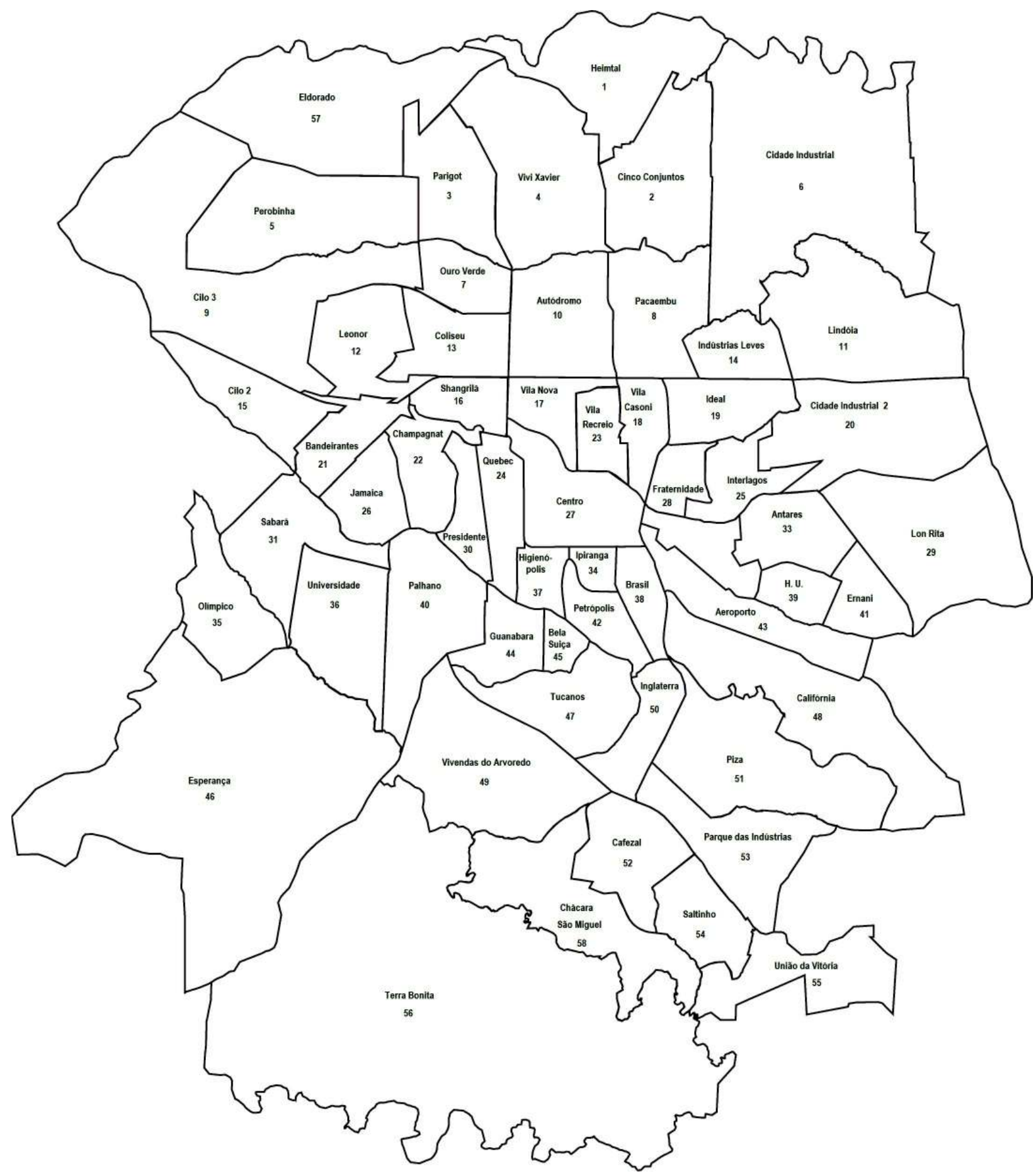

Figura 2 - Bairros da área urbana de Londrina

Em 2004, Londrina esteve entre os $10 \%$ dos municípios mais violentos que concentraram $71,8 \%$ dos homicídios ocorridos no Brasil. Classificou-se em $292^{\circ}$ lugar entre os $10 \%$ dos municípios de maiores taxas médias de homicídios, com 39,5 por 100.000 habitantes. Na classificação de homicídios juvenis, o município ocupou o $113^{\circ}$ lugar, com 102,7 mortes por 100.000 habitantes. Embora menosprezados nas análises de violência urbana, os óbitos causados por acidentes de transporte deixaram a cidade em $28^{\circ}$ lugar no cenário nacional, com a média de 131 mortes entre 2002 e 2004. Nas mortes causadas por armas de fogo, no mesmo período, ela ocupou o $198^{\circ}$ lugar, com 35,1 mortes (WAISELFISZ, 2007). 


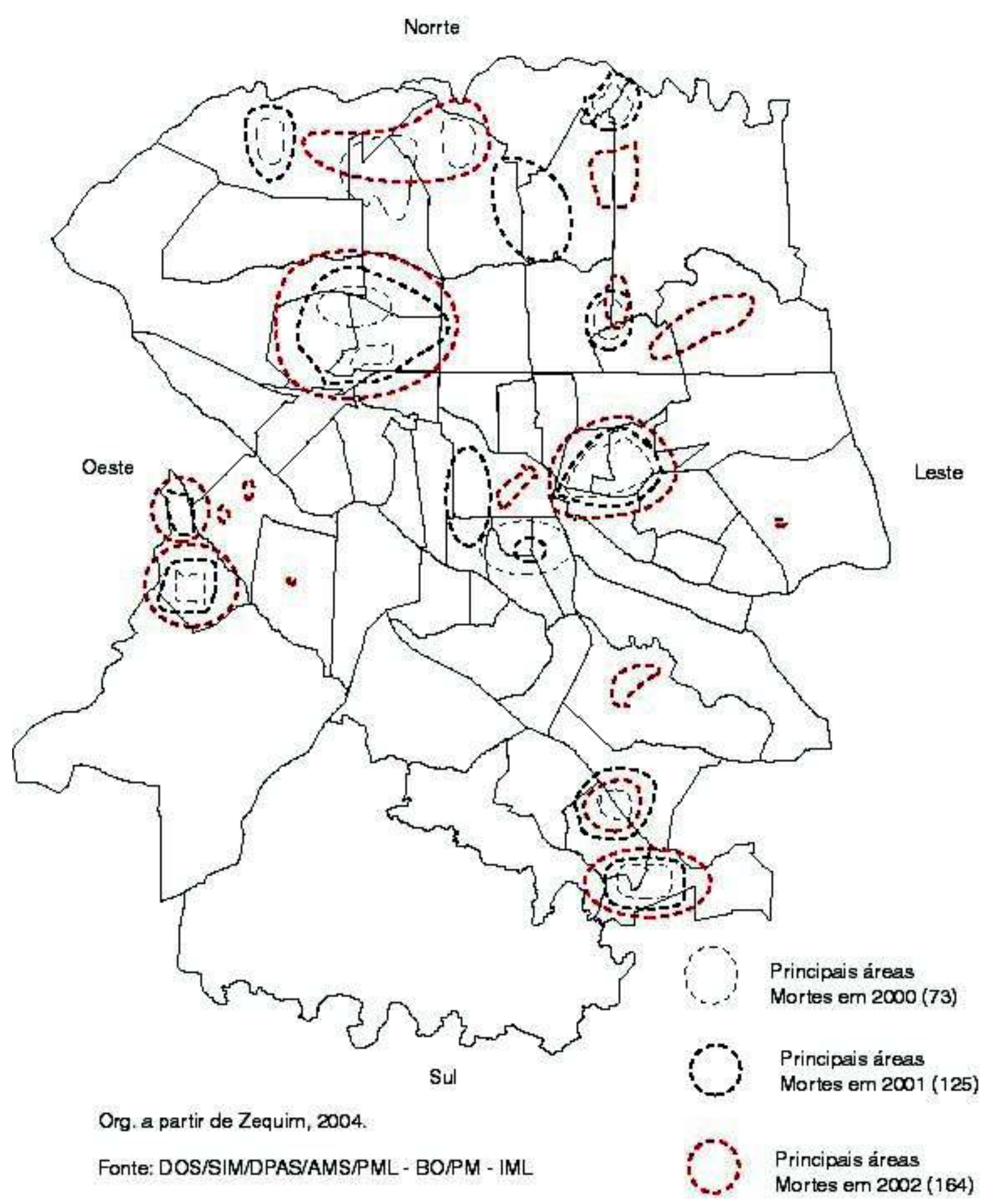

Mortes por homicídios: queimadura, armas branca, arma de fogo, asfixia mecânica, espancamento $e$ ignorado.

Figura 3 - Área urbana de Londrina: principais áreas de mortes de jovens - 2000 a 2002

Dados da pesquisa em desenvolvimento considerando todas as mortes por armas de fogo ocorridas no município entre 1999 a 2007 revelaram um máximo em 2003 seguido por uma leve diminuição e estabilidade, mas nunca inferior aos valores de 2001. Houve o aumento da participação de jovens entre 15 a 19 anos a partir de 2001, e um significativo crescimento nas mortes de crianças e adolescentes de 10 a 14 anos em 2007 (Figura 4). Esse dado mais recente revela os limites das 


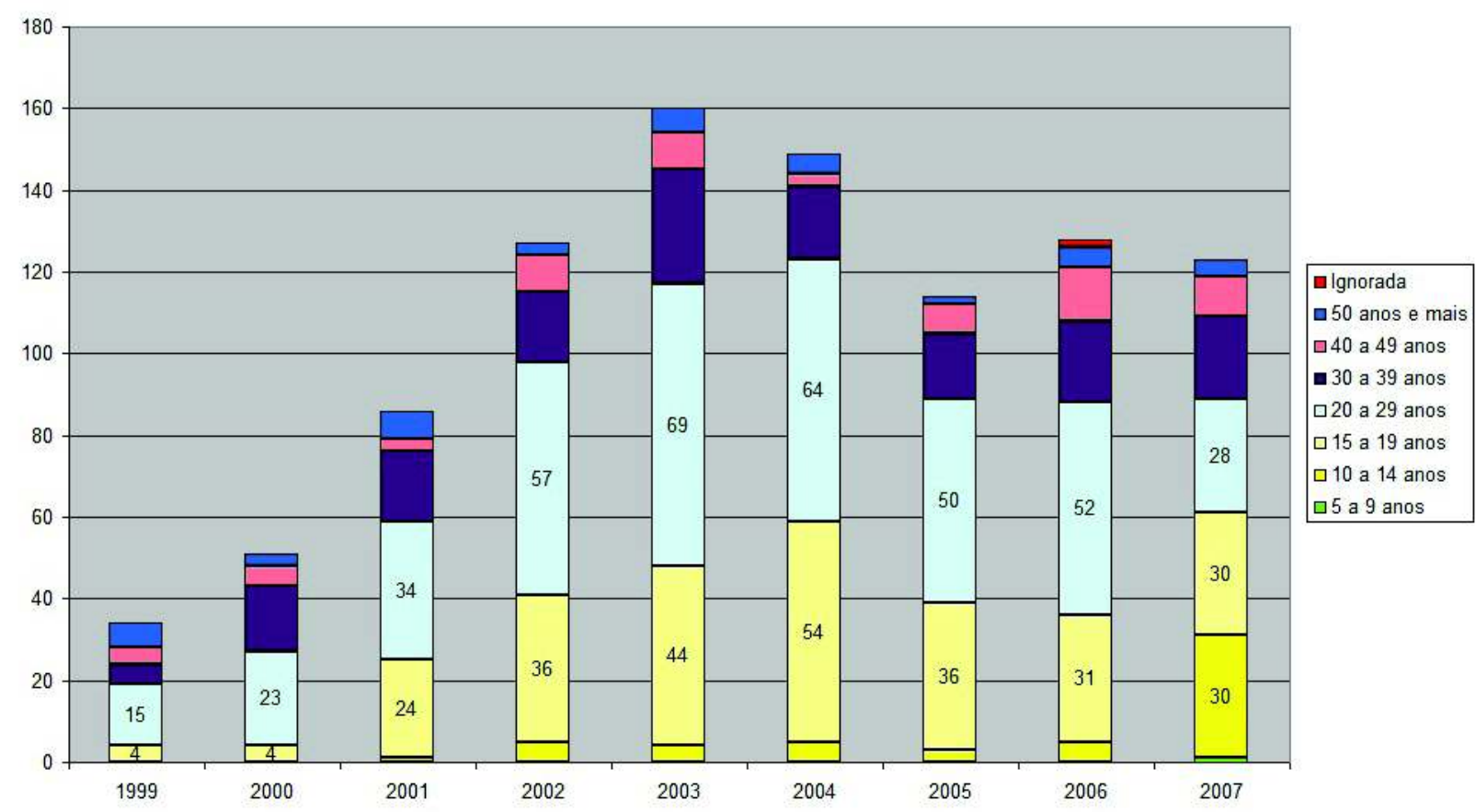

Fonte dos dados: Sistema de Informações sobre Mortalidade (SIM).

Figura 4 - Município de Londrina: Óbitos por armas de fogo e faixas etárias - 1999 a 2007

políticas públicas em relação à proteção à infância e à juventude de uma parcela de crianças e jovens. Obviamente um grau tão extremo de violência demonstrada pelas mortes por armas de fogo nessa faixa de idade (e em nenhuma das outras) são inaceitáveis se considerarmos que o direito à vida é a base sobre a qual se estrutura a cidadania.

Linhares (2007) identificou entre os menores infratores de Londrina uma associação muito forte entre a ação de atos ilícitos e o consumo de drogas, sendo que esses jovens compuseram o quadro dos assassinados na cidade. Conforme Souza (1998, p. 6) as favelas são, dentre todos os espaços segregados, os palcos preferenciais da territorialização protagonizada por traficantes de varejo. A distância curta entre a moradia e os locais da morte dos jovens constatada por Zequim (2004) indica a territorialização violenta de algumas ocupações irregulares pelo tráfico de drogas. Essas mortes mostram alguns elementos das estruturas sociológicas propostas por Briceño-Leon (2005), em especial quanto ao papel desempenhado pelo mercado de venda e compra de drogas ilícitas. Deve-se levar em conta a transformação do município de ponto de passagem para também local de processamento de drogas (refino de cocaína), com a prisão de pessoas nesses locais na área rural, e a conseqüente inserção da cidade em redes ilícitas mais amplas.

Teoricamente seria possível o estabelecimento de uma rede desse tipo sem a violência extrema revelada pelas mortes. Mas a estrutura atual do tráfico parece não ter um retorno a padrões menos violentos. Algumas notícias publicadas podem apontar para existência e a extensão dessa rede. Na rebelião acontecida em 2007 no Centro de Socioeducação (Cense) de Londrina os jovens internos estenderam uma faixa com as iniciais de uma facção criminosa paulista (GOUVEIA, 2007). Em novembro de 2006, a imprensa local noticiou indícios da sua atuação na cidade, negados pelo secretário de segurança do estado do Paraná. No mesmo mês um membro de sua cúpula, foi preso no estacionamento de um hipermercado na Zona Sul de Londrina (POMBO, 2006). A ironia ficou por conta de ele ter comprado, dias antes, uma residência num condomínio fechado - Alphaville I - cuja propaganda baseou-se na segurança e na vizinhança de padrão econômico e status elevados. Nesse 
caso é inevitável recorrer à citação da oposição entre favela e asfalto utilizada por Souza (1998, p. 7), pois é do "asfalto" que vêm os clientes e é lá que residem os financiadores.

O papel das cidades médias parece assumir importância nas redes ilícitas, pois houve, pelo menos, outros três casos de prisões de líderes do narcotráfico carioca residindo em capitais da região Nordeste. Tanto pelas oportunidades que elas apresentam quanto mais tênues forem os limites entre o legal e o ilegal. Possivelmente as cidades tidas como "médias" passaram a ter a preferência para a instalação de parte da cúpula das atividades narcotraficante, acompanhando o movimento de "desmetropolização", considerando aí a hierarquia de poder e não somente a ampliação das atividades. Essa é uma questão que permanecerá aberta, mas algumas considerações podem ser feitas no âmbito das escalas espaciais.

Considerando as três escalas do tráfico de drogas - planetária, metropolitana e intra-urbana (SOUZA, 2002, p. 438), Londrina apresenta a peculiaridade da proximidade da região das Três Fronteiras (Brasil, Argentina e Paraguai). Vulnerável e atravessada por redes de contrabando, pode ter contribuído para que a cidade deixasse o estágio de passagem e consumo para o de produção (refino de crack e cocaína) e ampliação do consumo. Drogas mais baratas vindas de redes hierarquizadas sediadas em outros lugares e aqui ramificadas no varejo alteraram o arranjo territorial local. Não somente por ter potenciais consumidores jovens, mas também pelo perfil das mortes e dos adolescentes infratores.

A formação de gangues e os confrontos resultam da disputa de território nos bairros. A mobilidade dos jovens no território urbano potencializa a ampliação da esfera da violência no espaço e no tempo. Os grupos estruturados em quase todas as zonas da cidade se vingam sucessivamente, a exemplo de gangues rivais do Jardim Nossa Senhora da Paz, Rua Pantanal e Jardim Leste-Oeste, todos na Zona Oeste (TRÁFICO..., 2004). Nesses lugares há comprovadamente tráfico de drogas por apreensões e episódios de choque pelo controle do território.

Parte dos fatores micro-sociais facilitadores da violência e o comércio ilegal de armas de fogo se refletem diretamente no número de óbitos. Embora se esperasse uma redução dessas mortes a partir de legislação mais restritiva no porte e posse de armas de fogo, a facilidade parece ter se mantido em Londrina. Boa parte chega às mãos dos adolescentes por intermédio de traficantes. Eles as repassam para os chamados "'aviões", meninos e meninas que comercializam drogas no varejo, ou são furtadas ou roubadas (POMBO, 2004). Nesse contexto estão as vinte e cinco mortes nos dois primeiros meses de 2008, das quais vinte foram de rapazes que tinham menos de 25 anos de idade. Das 222 armas de fogo apreendidas pela Polícia Civil entre janeiro e julho de 2007, 115 estavam em mãos de menores de 18 anos (GALEMBECK, 2007). Um novo tipo de droga vendida na cidade e o seu baixo preço também auxiliam na compreensão no aumento da violência no período. De acordo com a Promotora da Vara da Infância e Juventude da cidade houve uma mudança considerável no perfil dos atendidos envolvidos em crimes. Até 2001 os jovens menores de idade eram usuários de cola de sapateiro (tinner) e cometiam furtos. A mudança do perfil do jovem infrator acompanhou a "entrada maciça de crack na cidade". Em 2008, cerca de 3/4 dos adolescentes atendidos usavam armas, cometiam roubos e todos eram usuários de crack. Segundo ela, "a quantidade de roubos praticados pelos adolescentes passou a ser maior que a de furtos quando o tráfico de entorpecentes explodiu em Londrina de uma forma sistematizada" (PELEGRINO, 2008). Tal fato ampliou o mercado de venda e aluguel de armas ilegais, da mesma maneira que promoveu um aumento na quantidade de assassinatos de adolescentes por brigas pelo domínio de pontos de venda de drogas e dívidas.

Outros trabalhos mostram a violência cometida pelos jovens na cidade. O mapeamento das ocorrências de infrações cometidas por crianças e adolescentes na cidade de Londrina no período de 1999 - 2004 a partir de dados fornecidos pelo Centro Integrado de Atendimento ao Adolescente Infrator (CIAADI) revelou números crescentes (176 em 1999 para 470 em 2004) e ampliação da área onde elas ocorreram e delineamento do centro da cidade como área principal (MARCHETTI; ARCHELA, 2007). O levantamento junto aos menores infratores (CIAADI) revelou uma associa- 
ção muito forte entre a ação de atos ilícitos e o consumo de drogas, sendo que são esses jovens que compõem o quadro dos assassinados na cidade (LINHARES, 2007).

$\mathrm{O}$ resultado preliminar de pesquisa em andamento que utilizou como fonte os atendimentos a ferimentos por armas de fogo pelo Sistema Integrado de Atendimento ao Trauma e Emergências (SIATE) permite a localização por logradouro e bairro. Embora não se saiba quais deles resultaram em mortes posteriores e não classificados por faixas etárias, são as alternativas possíveis aos dados georreferenciados que a Secretaria de Segurança Pública do estado do Paraná mantém em sigilo aos pesquisadores e população em geral. Através deles podemos ter uma imagem desse tipo de agressão violenta que atinge os moradores da cidade.

Foram 217 atendimentos às pessoas de todas as idades que sofreram ferimentos por arma de fogo na área urbana de Londrina em 2008. O agrupamento da maior parte dos atendimentos revelou quatro áreas bem definidas e as mortes estão discriminadas no interior de cada bairro (Figura 5). A referência feita à localização dos assentamentos irregulares não deve ser associada aos locais onde os ferimentos aconteceram, mas serve para apontar que estão em bairros em que eles ocorreram.

Eles foram mais numerosos na zona central e bairros vizinhos a Leste (Área 1), da qual fazem parte os bairros Centro (14 atendimentos), Fraternidade (Assentamentos San Rafael, Vila Santa Terezinha e Fraternidade) e Interlagos (Assentamentos Marabá, Jardim Santa Fé, Vila Ricardo) (12 cada).

A segunda área tem como limite ao sul a Avenida Brasília (trecho urbano da BR-369) e ao norte o bairro do Heimtal. Formada pelos bairros Autódromo (7), Parigot (8), Vivi Xavier (4), Cinco Conjuntos (11) e Pacaembu (12). Nela aconteceram 51 atendimentos. Há várias ocupações irregulares nos fundos de vale vizinhos aos conjuntos habitacionais dos bairros Parigot, Vivi Xavier e Cinco Conjuntos, ao norte. Na direção sul, a rodovia BR-369 limita os bairros Autódromo, Pacaembu e Indústrias Leves.

O bairro União da Vitória no extremo da região sul apresentou o maior valor individual (23) e somado ao Parque das Indústrias (7), Piza (4) e Califórnia (8), formou a terceira região de ferimentos por arma de fogo. O primeiro hoje é composto pelas seções União da Vitória I, II, III e IV e o seu processo de crescimento aconteceu em prefeituras de Antonio Belinati. Não se quer fazer uma relação direta entre o ex-prefeito e as ocorrências, mas é uma informação acerca da origem recente do bairro e da sua ampliação. Mesmo com as pressões de movimentos populares posteriores por melhoria das condições de moradia, a cessão de terrenos e a construção de residências simples estão numa área que ainda demanda a ampliação de infraestrutura.

A quarta e última área localizada a Oeste deve ser vista pela formação de duas subáreas em função da ausência de ocorrências em bairros no limite sul (Jamaica, Champagnat e Presidente) e pela localização em relação às rodovias BR-369 e PR-445. Uma delas (4-a), limitada ao sul pelo trecho urbano da BR-369, é formada pelos bairros Coliseu e Leonor e somou doze atendimentos por ferimentos provocados por arma de fogo em 2008. A segunda subárea englobou (4-b) os bairros Olímpico, Sabará e o limite com o da Universidade na zona Oeste, com 5, 5 e 2 casos, respectivamente. Os ferimentos neste último bairro se localizaram em logradouros no limite com os outros dois bairros, daí o seu traçado.

O jovem que é violento e o que sofre violência moram e vivem num território onde são freqüentes ferimentos provocados por arma de fogo. A situação é crítica, mas algumas medidas preventivas e remediadoras foram tomadas pelo Governo do Estado do Paraná para o município. A participação constante da Promotoria da Infância e da Juventude junto aos problemas, a criação de locais específicos para menores infratores com projetos socioeducativos, a ação da Patrulha Escolar e a Polícia Comunitária (SCHEREMETA, 2005) e da Prefeitura indicam uma forma de uma resposta ao problema. Além disso, um grupo multidisciplinar preocupado com a violência que afeta crianças e adolescentes tem desenvolvido ações de combate e prevenção e se soma a outros projetos educativos. 


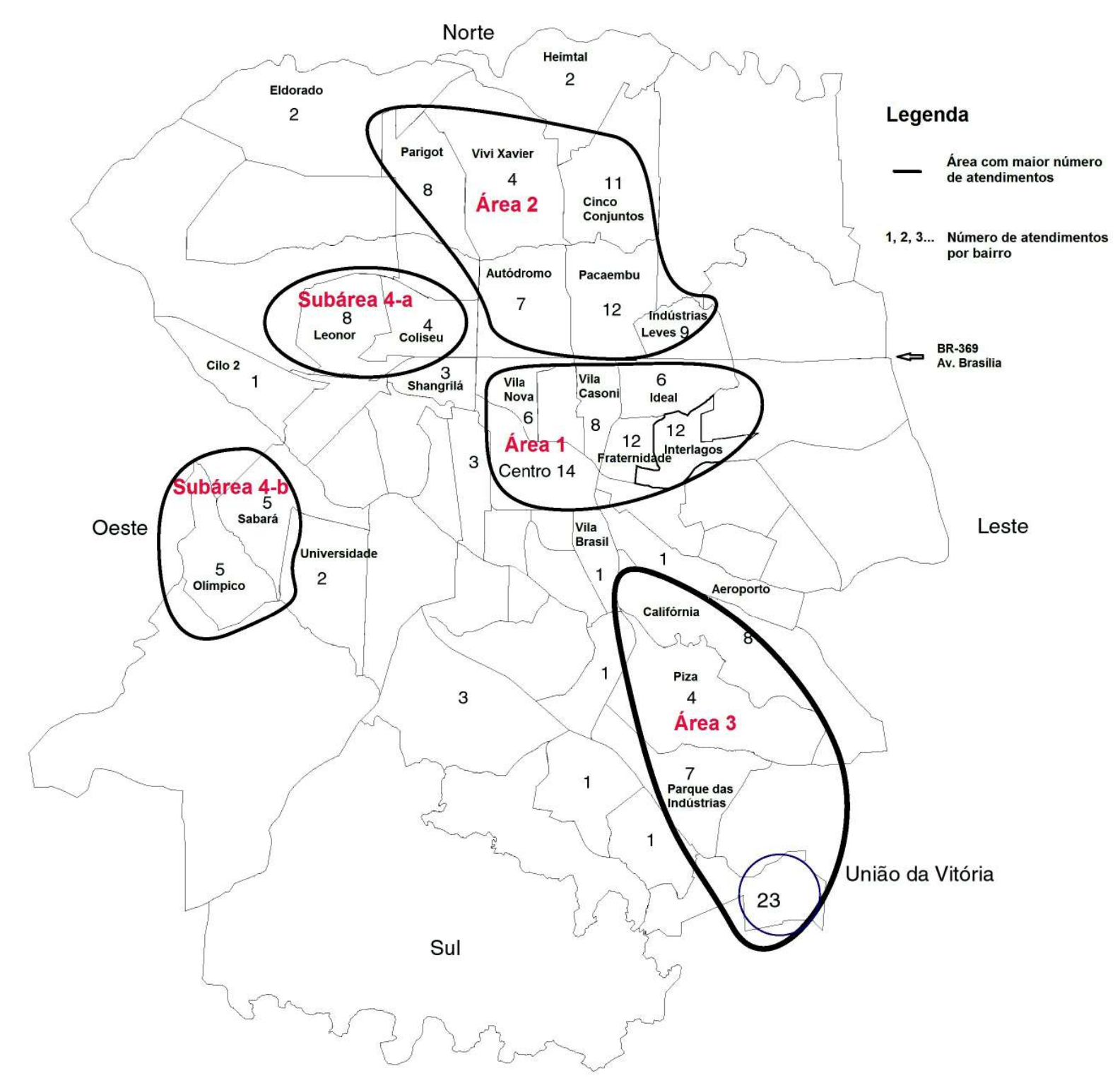

Fonte: PARANÁ (2009).

Figura 5 - Londrina: Atendimentos pelo SIATE por ferimento de arma de fogo -2008

As discussões colegiadas envolvendo os casos de violência buscam identificar formas de intervenção, por meio das quais ela possa ser combatida e a prevenção se institua como prática do cotidiano. Para isso, as ações contemplam visitas domiciliares regulares para o monitoramento das situações de violência pela constituição de grupos de intervenção psicossocial, congregando crianças, adolescentes e familiares adultos. São feitas reuniões periódicas entre a equipe da Universidade e representantes dos poderes públicos locais como Conselhos Tutelares e Promotoria da Infância e Juventude para dar os encaminhamentos jurídicos necessários. Há também o intercâmbio permanente com as instituições da rede pública e privada do município para articular ações e estratégias de proteção às crianças e adolescentes, evitando a fragmentação e sobreposição das intervenções (BARROS; SUGUIHIRO, 2003). 
As medidas ainda enfrentam os episódios acontecidos nas escolas de ensino fundamental e médio - furto de equipamentos, brigas entre alunos, presença de armas em sala de aula, rixas dentro ou nas proximidades das escolas. Isso indica que há uma ampliação dessas relações sociais violentas além dos locais de venda nas favelas e assentamentos urbanos que chegaram a provocar respostas na sociedade organizada, inclusive sindicais. Em maio de 2007, atitudes violentas promovidas por estudantes dentro das escolas - o seqüestro de uma diretora, assaltos a professores, apreensão de armas em sala de aula, depredação de material e agressões -, levou à manifestação dos docentes e do Sindicato dos Trabalhadores em Educação, a APP - Sindicato. (FADEL, 2007; ALUNOS..., 2007).

Envolvidos numa esfera violenta meso-social da cultura e de situação (características relativas à qualidade do espaço geográfico) desde o lar aos lugares públicos, os jovens terminam por se afastar de lugares que influem sobre o comportamento dos indivíduos onde poderiam ser desenvolvidas atitudes não violentas, como o desenvolvimento da capacidade do diálogo, como a escola. No total de 109 menores infratores entre 12 e 19 anos entrevistados predominou a escolaridade baixa (só o ensino fundamental). Entre os motivos do abandono escolar foram citados "por causa do crime" e a perda da vontade de estudar. O principal motivo citado para o ingresso no tráfico de drogas foi o "jeito mais fácil de conseguir dinheiro". Movidos pelo desejo de consumo $(60,65 \%)$, baixa escolaridade e desestímulo para a retomada dos estudos, esses jovens não raro afirmam um fatalismo de que não sabem se vão sobreviver por muito tempo (SANTOS, 2008).

\section{CONSIDERAÇÕES FINAIS}

A precariedade de moradias sozinha explicaria o aumento da violência urbana? Pensamos que não. Residências melhores servidas por creches, escolas e postos de saúde permitem uma vida em condições melhores aos moradores de assentamento e favelas, assim como o fornecimento de água tratada e energia elétrica. A constituição do Conselho Municipal de Habitação e de uma política de habitação são instrumentos valiosos e necessários no atendimento das necessidades de moradias adequadas para as populações de renda inferior a três salários mínimos (CONFERÊNCIA MUNICIPAL DE HABITAÇÃO, 2006). Mas não garantem que o bairro ou parte dele fique fora da esfera das mortes violentas.

Programas de transferência de renda para a população desfavorecida atingem um contingente razoável através de uma rede de 14 centros de referências de assistência social (CRAS) distribuídos por todas as regiões de Londrina, entre eles o que apresenta como condição a freqüência escolar. Mesmo assim, a cidade ainda apresenta uma face violenta aos seus jovens moradores nas ocupações irregulares que estão sob a territorialização do tráfico de drogas a despeito das ações específicas para lidar com o problema.

Há uma questão de escala espacial geográfica a ser decifrada em seus diferentes níveis (bairros, cidades, regiões, estados, nação, países) conjugada à estrutura de redes ilícitas criadoras de áreas de disputa de poder. A violência urbana quando vista a partir das mortes violentas de jovens se revelou concentrada em determinados bairros da cidade que têm ocupações irregulares, mas não em todos eles. Ao utilizarmos essa variável devemos buscar nas estruturas sociais os elementos para contextualizar as mortes desses jovens, mão-de-obra barata e preferencial na base hierárquica de varejo, a mais perigosa. A revisão bibliográfica variada e a tabulação dos dados da pesquisa indicaram a importância da contribuição de Briceño-Leon (2005). Nos espaços coletivos das ruas, praças e escolas podem-se identificar várias associações de diferentes níveis das estruturas sociológicas violentas, como a formação de gangues no processo de formação de identidade e virilidade e o mercado local de drogas (fomentadores da violência). O comportamento e as regras violentas da territorialidade do mercado do tráfico potencializam a incapacidade de resolver conflitos pelo diálogo, que deveria ter o seu lócus de aprendizado no ambiente familiar. Quando isso não acontece, as dificuldades atingem o cotidiano do ambiente escolar. Na estrutura sociológica mais geral, entre 
os fatores que originam a violência, os valores culturais (desejos de consumo e a incapacidade de realizá-los) têm uma relação destacada.

$\mathrm{Na}$ escala intra-urbana da cidade se distingue a trama de territorialidades que ora superpõe agentes distintos com interesses diversos, numa lógica ditada de fora da cidade. Grupos ligados a atividades ilícitas sediados fora da cidade buscam fincar e ampliar a rede de seus negócios, e a atuação na escala intra-urbana tem como metas os consumidores e a formação de uma rede de distribuição entre os jovens. As aspirações dos jovens são comuns e seus desejos de consumo também, em decorrência dos valores da sociedade do consumo. A renda é o fator diferenciador dos devedores (não obrigatoriamente consumidores) e o sentimento de pertencimento ao grupo como pré-condição de status traz uma contradição perversa. Para os jovens entram em jogo status e poder econômico numa sociedade em que ele ocupa o lugar desprestigiado por não ter renda (desemprego ou emprego com baixa remuneração) ou reconhecimento social. Quanto mais fácil for a possibilidade de ampliação do tráfico, seja pela debilidade de controle de fronteiras, seja pelo grau de corrupção policial, ele buscará entre os jovens com renda os prováveis consumidores e nos jovens desempregados os futuros pequenos comerciantes.

A contribuição de Souza (1996, 1998 e 2002) descrevendo o tráfico e as escalas espaciais possibilita não tomar essas mortes como um fato local isolado. A reunião dessas condições forma a estrutura que resulta no alto índice de mortalidade de jovens na cidade de Londrina. O levantamento das mortes causadas por armas de fogo na cidade entre 1999 e 2007 revelou um grande aumento entre crianças e adolescentes de 10 a 14 anos, fato inédito até então. Os ferimentos causados por armas de fogo, embora restritos a 2008, tornam possíveis a compreensão de que a violência se amplia para outros moradores e de várias idades. E independente da ampliação ou não dos territórios dominados pelo tráfico de drogas na venda de varejo, os territórios violentos se ampliam na cidade.

\section{REFERÊNCIAS BIBLIOGRÁFICAS}

ALUNOS seqüestram diretora de escola no Paraná. Portal G1, São Paulo. 04 abril,/2007. Disponível em $<$ http://g1.globo.com/Noticias/Brasil/0,,MUL18036-5598,00.html > Acesso em: [19 de Junho de 2007].

ARCHELA, Rosely Sampaio; BARROS, Miriam Vizintim Fernandes, org. Atlas Urbano de Londrina. Londrina: EDUEL, 2009.

BARÃO, Vera. Crime Organizado: Menores são usados para manter tráfico. Folha de Londrina. Londrina, 19/07/ 2 julh.,2002.

BARROS, Mari Nilza Ferrari; SUGUIHIRO, Vera Lúcia Tieko. A interdisciplinaridade como instrumento de inclusão social: desvelando realidades violentas. Olho no Futuro, Londrina, ano 6, n. 2, ago. 2003.

BRICEÑO-LEÓN, Roberto. Urban violence and public health in Latin America: a sociological explanatory framework. Cadernos de Saúde Pública, Rio de Janeiro, v.21, n. 6, p1629-1664, nov-dez. 2005. Disponível em: $<$ http://www.scielo.br/scielo.php?script=sci_arttext\&pid=S0102-311X2005000600002\&lng=en\&nrm= iso\&tlng $=\mathrm{en}>$. Acesso em: [16 de setembro de 2010]

LINHARES, Camila. Violência urbana e adolescentes em conflito com a lei em Londrina. Dissertação de mestrado. Geografia, Meio Ambiente e Desenvolvimento. 2007. Londrina. 190p.

CONFERÊNCIA MUNICIPAL DE HABITAÇÃO. Londrina. Política de Habitação. Londrina. COHAB-LD. 2006. Disponível em: < http://www.cohabld.com.br/Images/COHAB-LD-POLÍTICA-DE-HABITAÇÃO.pdf $>$ Acesso em: [19 de Junho de 2007].

CONFERÊNCIA MUNICIPAL DE HABITAÇÃO. Londrina. Conjuntos Habitacionais. S/D. Disponível em $<$ http://www.cohabld.com.br/conjuntos_habitacionais.asp $>$ Acesso em: [22 de setembro de 2010]

FADEL, Evandro. Professores discutem violência em escolas no Paraná. Portal Estadão, São Paulo. 10 Abr, 2007.

GALEMBECK, Glória . Adolescentes portam 52\% das armas apreendidas este ano. Jornal de Londrina, Londrina, 30 jul.,2007. 
GOUVEIA, Guilherme. Eleito, Belinati projeta retorno à Prefeitura. Jornal de Londrina. Londrina. 03. out. 2006. Disponível em: < http://portal.rpc.com.br/j1/manchete/conteudo.phtml?id=603286 > Acesso em: [19 de Junho de 2007].

GOUVEIA, Guilherme. Rebelião - Madrugada de fúria no Educandário de Londrina. Jornal de Londrina. Londrina. 06 março,2007.

LINHARES, Camila. Violência urbana e adolescentes em conflito com a lei em Londrina. 2007. 190p. Dissertação (Mestrado em Geografia, Meio Ambiente e Desenvolvimento.. Londrina. Universidade Estadual de Londrina.

LONDRINA. Prefeitura de Londrina. Perfil do Município de Londrina - 2005/2006 (Ano-Base 2004/2005). Londrina. Disponível em: <http://home.londrina.pr.gov.br/planejamento/perfil/perfil_2005_2006.pdf >. Acessado em: [19 de Junho de 2007].

LONDRINA. Prefeitura de Londrina. Prefeitura de Londrina. Perfil do Município de Londrina - 2009 (Ano-Base 2008). Londrina. Disponível em: $<$ http://www1.londrina.pr.gov.br/dados/images/stories/Storage/ sec_planejamento/perfil/perfil_2009_versao_final.pdf $>$. Acessado em: [30 de Setembro de 2010].

MARICATO, M. E. Metrópole na periferia do capitalismo: ilegalidade desigualdade e violência. São Paulo: Hucitec, 1996.

MARCHETTI, Márcio Catharin; ARCHELA, Rosely Sampaio. Mapeamento das Infrações Cometidas por Crianças e Adolescentes na Cidade de Londrina - PR no Período de 1999 - 2004. Londrina, 2007. Relatório de Pesquisa. Bolsa PIBIC/CNPq. 14p.

MICHAUD, Y. A Violência. São Paulo: Ática, 1989.

MINAYO, Maria Cecília de S.. Violência social sob a perspectiva da saúde pública. Cad. Saúde Pública. v.10, supl.1. Rio de Janeiro. Disponível em: $<\mathrm{http}: / / \mathrm{www}$. scielosp.org/scielo.php?script=sci_arttext\&pid=S0102$-311 X 1994000500002 \& \operatorname{lng}=p t \& n r m=i s o>$. Acesso em: [18 de Junho de 2007].

MISSE, Michel. Crime e pobreza: velhos enfoques, novos problemas. In: GONÇALVES, M.A.; VILLAS-BOAS, G. (orgs.). O Brasil na Virada do Século. Rio de Janeiro: Relume-Dumará, 1995.

MISSE, Michel. Cinco teses equivocadas sobre a criminalidade urbana no Brasil. < Disponível em: $<$ http://www.necvu.ifcs.ufrj.br/arquivos/cinco\%20Teses\%20Equivocadas\%20sobre\%20a\%20Criminalidade\%20Urbana\%20no\%20Bra....pdf > . Acesso em: [19 de Junho de 2007].

PARANÁ (S/D) Tribunal Regional Eleitoral. Resultados de todas as eleições municipais. Disponível em < http://www.tre-pr.jus.br/internet2/tre/estatico/eleicoes/anteriores/index.jsp> Acessado em: [22/10/2010].

PARANÁ (S/D). Sistema de registro e estatística de ocorrências. Corpo de Bombeiros do Paraná. Disponível em: < http://www.bombeiroscascavel.com.br/registroccb/imprensa.php> Acessado em: [20/10/2009].

PELEGRINO, Érika. Tráfico de drogas muda o perfil dos adolescentes infratores. Jornal de Londrina. 21/01/ 2008. Disponível em: $<$ http://portal.rpc.com.br/jl/geral/conteudo.phtml?tl=1\&id=730907\&tit=Trafico-de-drogas-muda-o-perfil-dos-adolescentes-infratores $>$. Acesso em: [21 de Janeiro de 2008].

POMBO, Luciana. QUEM compra a arma tem que assumir tudo. Jornal de Londrina, Londrina, 29 out., 2004. POMBO, Luciana. Financiador do PCC é preso em Londrina. Folha de Londrina. Londrina. 23.11.2006. Disponível em: http://www.bonde.com.br/folha/folhanew.php?id_folha=2-1-3-24260-20061123 Acessado em: [16/09/2010].

SANTOS, Zilma. Maioria dos 25 homicídios do ano tem ligação com o tráfico. Jornal de Londrina. Londrina. 25 fev.,2008. p. 4.

SCHEREMETA, Marcos Teodoro. A Polícia Comunitária na Polícia Militar do Paraná. Curitiba (?). Fev. 2005. Disponível em: <http://www.diaadiaeducacao.pr.gov.br/portals/portal/patrulhaescolar/pdf/policia_comunitaria.pdf $>$ Acessado em: [19 de Junho de 2007]. 7p.

SOUZA, Marcelo Lopes de. As drogas e a "questão urbana" no Brasil. A dinâmica sócio-espacial nas cidades brasileiras sob a influência do tráfico de tóxicos. In: CASTRO, Iná et al. (orgs.). Brasil: questões atuais da reorganização do território. Rio de Janeiro: Bertrand Brasil. 1996.

SOUZA, Marcelo Lopes de. Tráfico de Drogas e Fragmentação do tecido sóciopolítico- espacial no Rio de Janeiro. 1998. Disponível em: < http://bibliotecavirtual.clacso.org.ar/ar/libros/anpocs/marce.rtf $>$.Acesso 
em: [10 de Março de 2008].

SOUZA, Marcelo Lopes de. Mudar a cidade. Uma introdução crítica ao planejamento e à gestão urbanos. 4 ed. Rio de Janeiro: Bertrand Brasil, 2002.

TONELLA, Celene. O Urbanismo do Desespero - um estudo dos processos de luta pelo espaço urbano no Paraná - 1985/1992. Assis, 1997. Tese (Doutorado em História) - Universidade Estadual Paulista Júlio de Mesquita Filho.

TRÁFICO e gangues: dois vilões da juventude: PM trabalha na prevenção através de dois programas. Folha de Londrina, Londrina. 29 out., 2004.

ZALUAR, Alba; NORONHA, José C. de; ALBUQUERQUE, Ceres. Violência: pobreza ou fraqueza institucional?. Cad. Saúde Pública. v.10. Supl. 1, Rio de Janeiro. Disponível em: <http://www.scielosp.org/ scielo.php?script $=$ sci_arttext\&pid $=\mathrm{S} 0102-311 \mathrm{X} 1994000500016 \& \operatorname{lng}=\mathrm{pt} \& \mathrm{nrm}=\mathrm{iso}>$. Acesso em: $[18 \mathrm{de}$ Junho de 2007].

WAISELFISZ, Julio Jacobo. Mapa da violência dos municípios brasileiros. Brasília: Organização dos Estados Ibero-Americanos para a Educação, a Ciência e a Cultura, 2007.

ZEQUIM, Maria Angelina. Territórios da Ilegalidade e Muros Invisíveis em Londrina: análise geográfica dos homicídios resultantes da violência urbana 2000 a 2002. Londrina, 2004. Dissertação (Mestrado em Geografia, Meio Ambiente e Desenvolvimento) - Universidade Estadual de Londrina.

Trabalho enviado em maio de 2011

Trabalho aceito em julho de 2011 